\title{
Identifying Vulnerable Populations in Subtropical Brisbane, Australia: A Guide for Heatwave Preparedness and Health Promotion
}

\author{
Margaret Loughnan, Nigel Tapper, and Thu Phan \\ Monash Weather and Climate, School of Geography and Environmental Science, Monash University, Clayton, VIC 3800, Australia \\ Correspondence should be addressed to Nigel Tapper; nigel.tapper@monash.edu
}

Received 13 November 2013; Accepted 25 December 2013; Published 17 February 2014

Academic Editors: F. Janssen and A. Ren

Copyright (C) 2014 Margaret Loughnan et al. This is an open access article distributed under the Creative Commons Attribution License, which permits unrestricted use, distribution, and reproduction in any medium, provided the original work is properly cited.

Building healthy societies is a key step towards climate resilient communities. Ill health is related to increased risk during heat events and is disproportionally distributed within and between communities. To understand the differences in the spatial distribution of climate related health risks and how this will change in the future we have undertaken a spatiotemporal analysis of heatwave risks in urban populations in Brisbane, Australia. The aim of this was to advise emergency managers and public health authorities of highrisk areas during extreme heat events (EHEs). The spatial distribution of heat related morbidity identified areas of high healthcare service demand during EHEs. An index of risk was developed based on social and environmental determinants of vulnerability. Regression analysis was used to determine the key drivers of heat related morbidity from the index. A weighted map of population vulnerability was produced which identified the high risk areas and provided key information to target public health interventions and heat stress prevention policy. The predicted changes in high risk populations such as the proportion of elderly people living in urban areas were also mapped to support longer term adaptation and develop health care infrastructure and health promotion strategies.

\section{Introduction}

In Australia, heatwaves kill more people than any other natural hazard. The unequal distribution of risk between and within communities means that the elderly, the frail, and the poor experience the greatest risk. The January 2009 heatwave in south-eastern Australia resulted in the loss of hundreds of lives, disrupted power supplies and transport infrastructure, and, most importantly, placed a considerable demand on public health facilities and emergency services [1]. Vulnerability indices are useful tools to inform adaptation and increase community and organisational resilience to natural hazards such as heatwaves. Emergency managers, local governments, and public health authorities can use this approach to engage in both bottom-up and top-down adaptation strategies. When targeted heat alert systems are in place, excess mortality and morbidity during heatwaves are largely avoidable. This study has provided a "mapping tool," the use of which will strengthen public health and emergency management policy to reduce heat-related mortality and morbidity.

There is a rapidly growing body of research addressing heatwave related risk in many of the world's larger cities, particularly in temperate and hot arid environments; less information is available for subtropical cities. In most cases, this has been limited to understanding the temperature health relationship. To date there are no holistic approaches to understanding heat health temperature thresholds, heatwave vulnerability, or health service demand during extreme heat events. The main purpose of this paper is to develop a holistic approach by (a) describing temperature thresholds above which mortality and morbidity increase, (b) developing a spatial index of vulnerability providing a visual tool for heatwave preparedness and response, and (c) describing how heat-related risk may change in the future in Brisbane, a subtropical city in Australia. 
An extreme heat event, or "heatwave," is a period of hot weather when ambient temperatures are high enough to pose a serious risk to the health of exposed individuals and populations and to public and private infrastructure [2]. There is no universal definition of a heatwave and local definitions of excessive heat are determined by the deviance from usual weather patterns in a particular area and the resulting impact on the residents and environment. The Intergovernmental Panel on Climate Change (IPCC) has concluded in its recent Special Report "Managing the Risks of Extreme Events and Disasters to Advance Climate Change Adaptation" (SREX) [3] that it is very likely that the length, frequency, and/or intensity of heatwaves will increase over most land areas during this time.

Heatwaves are linked to marked short-term increases in mortality of exposed populations. Recorded heatwaves across Western Europe in 2003 resulted in 50,000 to 70,000 excess deaths over the summer months $[4,5]-15,000$ of these deaths occurring during a three-week period in France [6]. Heatwave events in Athens [7], England and Wales [8, 9], Chicago [10], Portugal [11], Netherlands [12], Spain [13], California [14], and Russia [15] have also resulted in large losses of life.

Reports from subtropical countries are much fewer in number. This is a major concern as Battisti and Naylor (2009)[16] have indicated that there is a greater than $90 \%$ probability that warm season temperatures in tropical and subtropical areas in the future will exceed the most extreme warm season temperatures recorded during the last century (1900 to 2006). In addition, rapid unplanned urbanisation of cities in developing countries will enhance this effect by intensification of the urban heat island (UHI). Recent heat health research in Japan, South Korea, and Hong Kong has shown a relationship with hot weather [17-19]. Heat health research is relatively new in South Korea and developing countries such as China, India, and Bangladesh, but similar patterns in mortality and morbidity are noted [20-23].

In Australia, heatwaves have contributed to at least 4287 deaths over the period of 1802 to 2003, double the fatalities caused by floods or cyclones over the same time [24]. In late January 2009 a severe heatwave across south-eastern Australia led to an estimated excess mortality of $32.4 \%$ in Adelaide [25] and 374 excess deaths over three days in Victoria [26]. In Queensland, 22 deaths and 350 injuries were reported after a heatwave in January 2000 [27]; in Brisbane 75 excess deaths occurred during a short heatwave in February 2004 [28].

A study of the heat impacts on mortality for the population of Brisbane has shown that hot temperatures have an acute, short-term effect. Yu et al. [29] found that the effects of extreme heat on mortality were most evident at a lag of 3 days and for people aged 85 years and older. Persons dying from cardiovascular diseases (all age groups) showed a strong effect at lag of 1 day [30]. While Huang et al. [31] found an impact of temperature on years of life lost, this was greatest on the day of exposure. Tong et al. [28] indicated that emergency hospital admissions begin to rise at a maximum temperature threshold of about $27^{\circ} \mathrm{C}$. These findings support the importance of the identification of vulnerable population subgroups prior to summer to allow targeted interventions and support to minimise the risk of heat-related morbidity and mortality.

Heatwaves in Australia result in considerable mortality and morbidity [24]. As climate change progresses and summer temperatures increase [32], adverse health effects during extremely hot weather will increase the demand for emergency services such as ambulances. To prepare for this is an important part of emergency service and public health authority planning. Communities can adapt to extreme heat events by engaging with public health authorities, emergency managers, local governments, and nongovernment organisations to reduce heat exposure during periods of extreme summer temperatures. Developing targeted heatwave adaptation planning can be achieved by changing behaviours and living environments and by building resilience aided by understanding the character of high risk areas.

To date several studies have reported heatwave thresholds for deaths and hospitalisations in Brisbane $[1,28,33-$ 35]. Information linking vulnerability to heat exposure to population subgroups or specific places has not been undertaken. This information is essential for successful climate change adaptation. This study developed a "tool" to map population vulnerability to extreme heat events in large urban areas, aiming at assisting emergency managers and public health authorities develop adaptation strategies to cope with extreme heat and to provide a decision making framework to guide future adaptation planning.

\section{Methods}

The study included three components that influence heat health relationships, beginning with the identification of heat health thresholds for the city of Brisbane and the surrounding metropolitan area. It is important for the implementation of heat health alert systems that thresholds are easy to understand and easy to calculate using routine daily Bureau of Meteorology (BoM) forecasts.

\subsection{Weather Data}

Threshold Calculation. Daily weather data for the city of Brisbane were purchased from the Australian Bureau of Meteorology for the period of 2003 to 2011. This included daily maximum and minimum temperatures, daily maximum dewpoint temperature, and daily average wind speed. The 24-hour average temperature from $9 \mathrm{am}$ to $9 \mathrm{am}$ was calculated and is referred to as mean $T$. Daily apparent temperature (AT) was calculated using the following formula:

$$
\begin{aligned}
\mathrm{AT}= & -2.653+\left(0.994 * \text { temperature }^{\circ} \mathrm{C}\right) \\
& +0.0153 *\left(\text { dewpoint temperature }{ }^{\circ} \mathrm{C}\right)^{2}
\end{aligned}
$$

(after O’Neill et al. [36]).

AT is a heat stress index that includes a measure of humidity; it is often referred to as the "feels like" temperature. This provides an indication of the effects of oppressive weather on human health. However this is not easy to forecast 
using routine Bureau of Meteorology data but can be used to caution the public on a daily basis. The temperatures at which median morbidity increased from the baseline or expected rate were identified as the lower limits for extreme heat thresholds. This method has been used successfully in Melbourne and regional Victoria [37, 38].

2.2. Morbidity Data. Daily morbidity data consisted of all emergency ambulance callouts in the city of Brisbane and surrounding metropolitan area each day for the period of $1 / 7 / 2003$ to $4 / 8 / 2011$. The spatial location of each ambulance callout was recorded by postal area (PoA) and/or locality. If PoA information is missing, it is updated by linking locality and PoA GIS layers. The PoA value of ambulance data is assigned to PoA which covers the largest area intersecting with the locality feature. Days with excess emergency ambulance calls were identified using a seasonal decomposition procedure. All statistical analyses were done using SPSS [39].

2.3. Spatial Index of Vulnerability. During heatwaves, population mortality and morbidity are not distributed evenly across cities. There are areas of high risk and areas of lower risk. The second component of the study was to develop a spatial index of population vulnerability to extreme heat. Emergency ambulance callouts on days that exceeded the threshold temperatures for Brisbane were used to create decile maps of emergency service demand. A comprehensive literature review $[1,5,25,28,37,40-44]$ identified the key components of vulnerability based on analysis of recent heatwaves worldwide. Risk factors for which data were readily available at an appropriate spatial scale were selected. This ensures the replicability of the index for other cities and for future analysis.

The index included 11 variables measuring environmental, demographic, and health factors known to affect health outcomes during heatwaves. Table 1 presents data sources and summarises how these variables were determined. These variables were collected at a postal area (PoA) level for analysis. The variables were regressed against the emergency health measure (emergency ambulance callouts) to identify which of the vulnerability variables best represented the spatial distribution of heat-related health outcomes. A variable is entered into the model if the significance level of its $F$ value is less than 0.05 and is removed if the significance level is greater than 0.10 . Colinearity is a problem when the variables in the regression are not independent. A condition index greater than 15 indicates a possible problem and an index greater than 30 suggests a serious problem with colinearity. The model producing the highest $R^{2}$ values that showed no indication of colinearity was selected. Variables that made a significant contribution to the spatial representation of adverse health outcomes were used to make a weighted index of vulnerability. The weighted index was made into deciles and subsequently mapped to show areas where predicted vulnerability and measured risk (emergency health outcomes) intersect (Figure 1). A Spearman correlation was done using the decile values of the weighted VI and the decile values of the ambulance callouts for each PoA to determine the citywide association between these variables.
2.4. Temporal Analysis. The third part of the study addressed a need to develop longer term strategies to protect communities. Communities and institutions change over time so predicting changes in vulnerability based on current socioeconomic conditions is not acceptable. However, predicting changes in the highest risk group, people aged 65 years and older, is possible as population projections are available for Brisbane until 2031.

Population projections for the area-based total population can be used to predict changes in urban density; urban density is a driver of the UHI and was a variable included in the analysis. Population projection data for Brisbane were provided by Queensland Government [45]. Predicted changes in total population and the proportion of persons aged 65 years and older were mapped to show high risk areas and how they relate to current areas of increased vulnerability.

\section{Results}

3.1. Threshold Temperatures. This study presents a representation of heat-related health risks in urban areas in and around Brisbane and the resultant increases in emergency ambulance callouts. Threshold temperatures for an increase in emergency ambulance calls are shown in Table 2.

A threshold using mean $\mathrm{T}$ of $34^{\circ} \mathrm{C}$ showed the most consistent effect of heat on emergency service demand. When the mean $T$ reached $34^{\circ} \mathrm{C}$ a $9 \%$ increase in emergency ambulance callouts was observed. This was chosen as a suitable threshold for the Brisbane area.

3.2. Development of Spatial Vulnerability Index. The regression analysis indicated that three variables from the index (as shown in Table 1): aged care facilities (ACF), singleperson households (person aged over 65 years), and urban design, were the best predictors of vulnerability in Brisbane city. The unstandardised coefficients (see Table 3) from the regression equation were used to weight the vulnerability index (see weighted vulnerability in (2)). The condition index was 4.8 ; this is not suggestive of multicolinearity in this model. The decile values for vulnerability in postal areas are shown in Figure 1. Areas labelled as decile 10 indicate highest vulnerability and decile 1 the lowest. Consider the following:

$$
\begin{aligned}
& \text { weighted vulnerability index } \\
& \qquad \begin{array}{l}
=2.450 * \mathrm{ACF}+1.248 \\
\quad * \text { single-person households (aged } 65+\text { years) } \\
\quad+0.083 * \text { urban design. }
\end{array}
\end{aligned}
$$

A Spearman correlation between the weighted VI and emergency service demand (morbidity data) was $\mathrm{RHO}=$ $0.617, P=0.001$. The weighted VI explains $61.7 \%$ of the variability in ambulance callouts on days exceeding the threshold of $34^{\circ} \mathrm{C}$.

Figures 3 and 4 show the projected population distributions for Brisbane from 2006 to 2031. These are presented as quintiles for population density (persons per $\mathrm{km}^{2}$ ) and the proportional change in the older population (persons 
TABLE 1: Risk factors and their data sources.

\begin{tabular}{|c|c|c|}
\hline Risk factor & Data sources & Derivation of the variable \\
\hline Age $(0-4,65+)$ & ABS $^{*}$ BCP $^{\#}$, Table $1[49]$ & $\%$ population under 4 and over 65 \\
\hline Aged care facilities (ACF) & Department of Health and Ageing & $\%$ ACF within city \\
\hline $\mathrm{SES}^{* *}$ & ABS, SEIFA $^{\# \#, ~ T a b l e ~} 3[49,50]$ & SEIFA \\
\hline Urban design & ABS, BCP, Table 31 [49] & $\%$ dwellings which are not single dwellings \\
\hline Single-person households & ABS, BCP, Table 22 [49] & $\%$ single-person households \\
\hline Need for assistance (measure of disability) & ABS, BCP, Table 17 [49] & $\begin{array}{l}\% \text { population who need assistance with core } \\
\text { daily activities }\end{array}$ \\
\hline Population density & ABS, BCP, Table 1 [49] & Population (under 4 and over 65 ) $/ \mathrm{km}^{2}$ \\
\hline Ethnicity & ABS, BCP, Table 12 [49] & $\begin{array}{l}\% \text { population who speak a language other } \\
\text { than English at home }\end{array}$ \\
\hline UHI & $\begin{array}{l}\text { MODIS (Terra) Land surface } \\
\text { Temperature and Emissivity Monthly L3 } \\
\text { Global } 0.05^{\circ} \text { CMG (2005-2009) }\end{array}$ & Mean LST in summer $\left({ }^{\circ} \mathrm{C}\right)$ \\
\hline Land cover & ABS, Meshblock & $\begin{array}{l}\% \text { areas which are parklands or agricultural } \\
\text { lands }\end{array}$ \\
\hline Accessibility to emergency service & Google maps & $\begin{array}{l}\text { Shortest travelling distance and fastest } \\
\text { traveling time from centroid of PoA to } \\
\text { emergency service, extracted from Google } \\
\text { maps using SAS version } 9.2 \text { (Zdeb 2010) [51] }\end{array}$ \\
\hline
\end{tabular}

*ABS: Australian Bureau of Statistics, 2006.

\# BCP: Basic Community Profile.

${ }^{* *}$ SES: Socioeconomic Status.

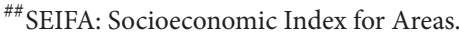

TABLE 2: Summer-time threshold temperatures for increased ambulance calls in Brisbane (based on data from 1/7/2003 to 4/8/2011).

\begin{tabular}{lccccccccc}
\hline City & Total days & $T_{\max }$ & Increased morbidity & $T_{\min }$ & Increased morbidity & Mean $T$ & Increased morbidity & AT & Increased morbidity \\
\hline Brisbane & 2956 & $36^{\circ} \mathrm{C}^{*}$ & $2.5-12 \%$ & $26^{\circ} \mathrm{C}^{*}$ & $2.5 \%$ & $34^{\circ} \mathrm{C}^{*}$ & $9 \%$ & $40^{\circ} \mathrm{C}^{*}$ & $4-11 \%$ \\
\hline
\end{tabular}

${ }^{*}$ Temperatures noted for $T_{\max }, T_{\min }$, mean $T$, and AT are the lower thresholds.

TABLE 3: Stepwise regression analysis of emergency ambulance callouts and heat related variables.

\begin{tabular}{|c|c|c|c|c|}
\hline \multirow{2}{*}{ Model } & \multicolumn{2}{|c|}{ Unstandardized coefficients } & \multirow{2}{*}{$t$} & \multirow{2}{*}{ Significance } \\
\hline & $B$ & Std. error & & \\
\hline \multicolumn{5}{|l|}{ (1) } \\
\hline Constant & 4.342 & 0.773 & 5.620 & 0.000 \\
\hline $\mathrm{ACF}$ & 3.272 & 0.613 & 5.335 & 0.000 \\
\hline \multicolumn{5}{|l|}{$(2)$} \\
\hline Constant & 0.593 & 1.171 & 0.507 & 0.613 \\
\hline ACF & 2.533 & 0.606 & 4.178 & 0.000 \\
\hline Single-person households & 1.612 & 0.394 & 4.093 & 0.000 \\
\hline \multicolumn{5}{|l|}{ (3) } \\
\hline Constant & 0.046 & 1.166 & 0.040 & 0.968 \\
\hline $\mathrm{ACF}$ & 2.450 & 0.595 & 4.119 & 0.000 \\
\hline Single-person households & 1.248 & 0.411 & 3.037 & 0.003 \\
\hline Urban design & 0.083 & 0.032 & 2.550 & 0.012 \\
\hline
\end{tabular}




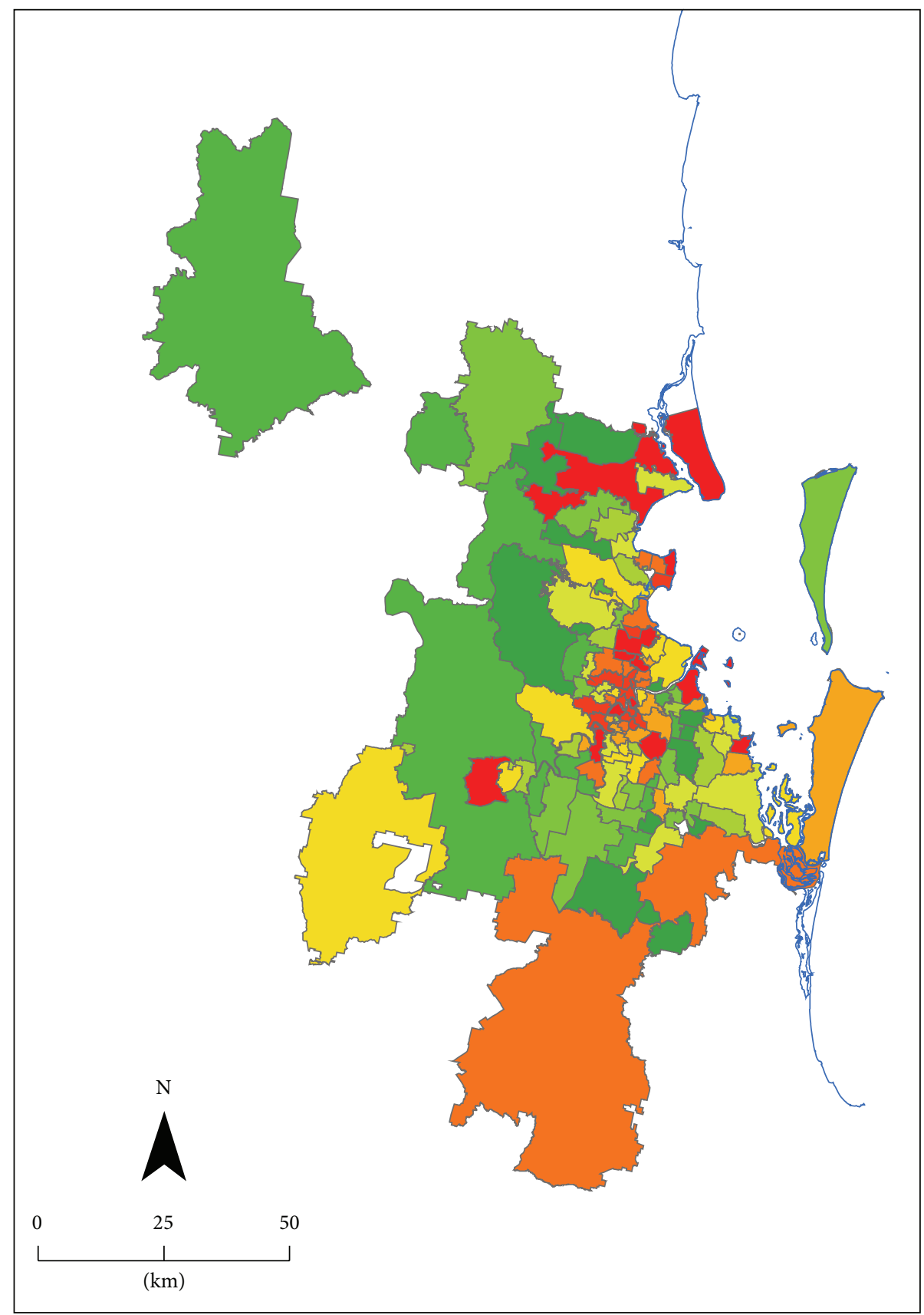

Weighted vulnerability index

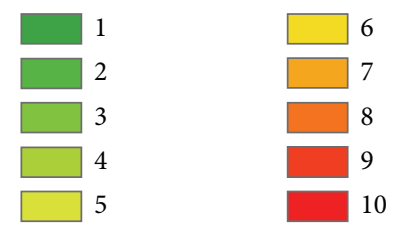

FIGURE 1: Weighted vulnerability index for Brisbane. Decile 1 indicates lowest vulnerability while decile 10 indicates highest vulnerability (based on 1/7/2003-4/8/2011 emergency ambulance callout data). 


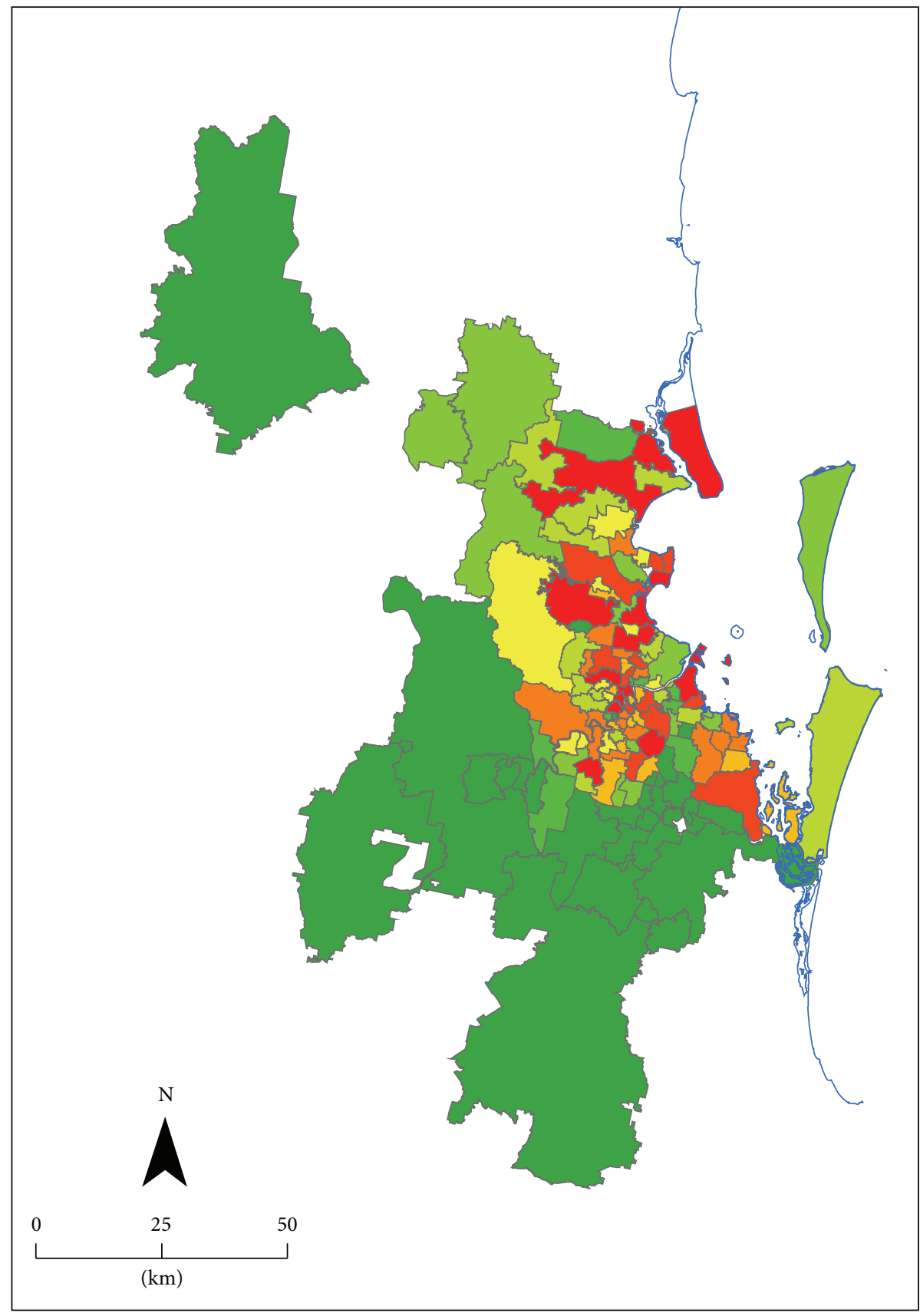

Ambulance callouts

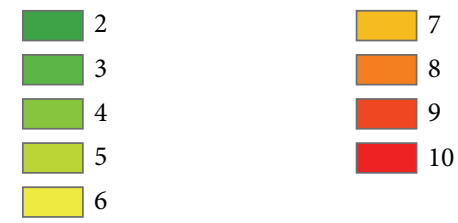

Figure 2: Spatial distribution of decile values of ambulance callouts on hot days (days when mean $T$ equalled or exceeded $34^{\circ} \mathrm{C}$ ) in $\mathrm{Brisbane}$ (based on 1/7/2003-4/8/2011 data). 


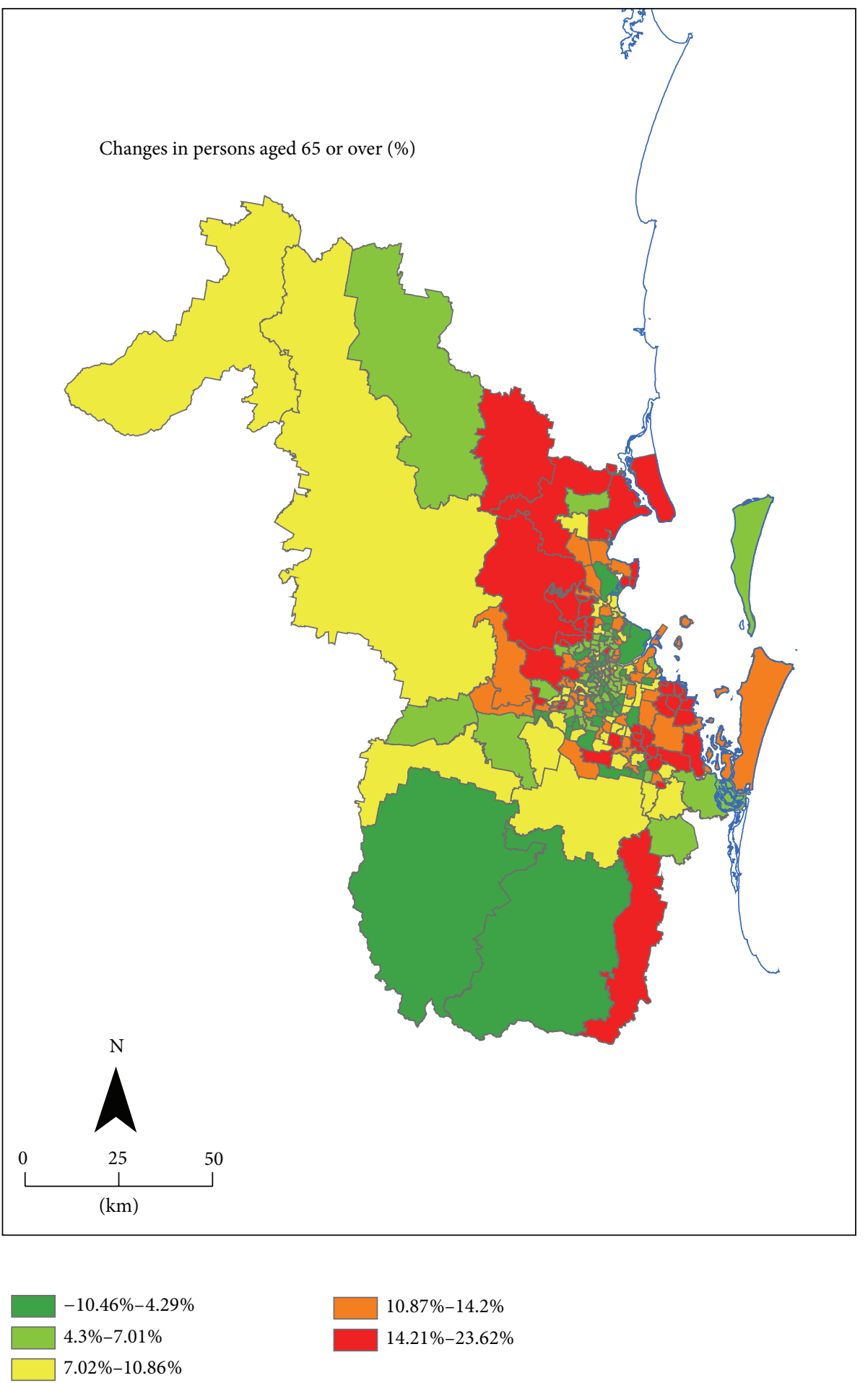

FIGURE 3: Changes in proportion of elderly people in Brisbane between 2006 and 2031 by Statistical Local Area (SLA).

aged $65+$ years). The proportional increase in older people is greater in the periurban areas to the north and south of the Brisbane area whereas the increase in population density is more concentrated in the periurban areas to the west of the city. However there are notable areas of crossover where areas with increased population density also include a greater proportion of older people. These areas should be highlighted for implementation of adaptation measures to minimise heatwave risk.

Figure 5 highlights an interesting pattern of relative change in AHO between nonhot days and hot days. While $\mathrm{POA}$ in the outer suburbs of southern Brisbane and around the city of Brisbane generally are reported with increased ambulance callouts, POA in the northern part of 


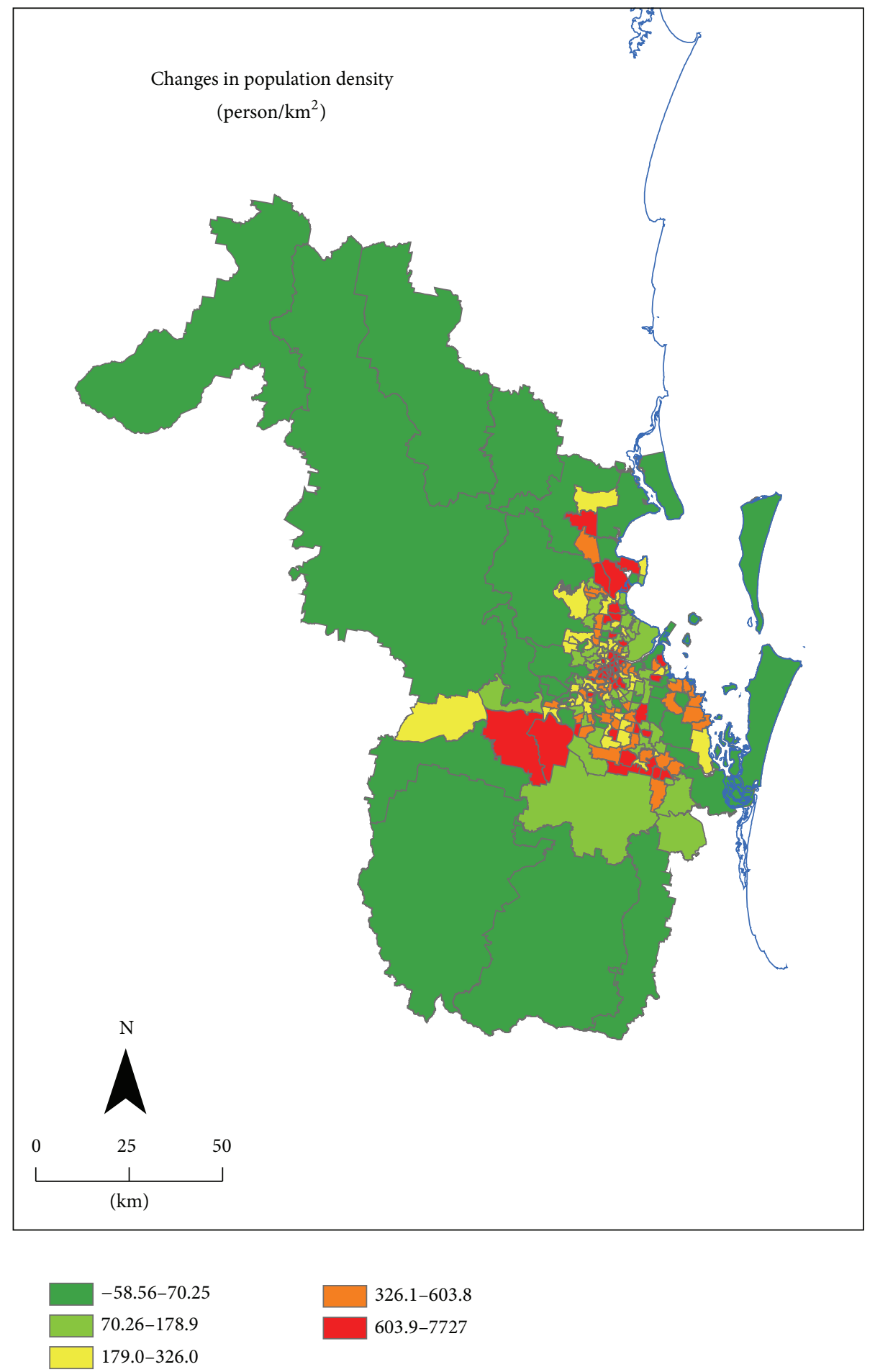

Figure 4: Change in population density between 2006 and 2031 by Statistical Local Area (SLA) in Brisbane.

Brisbane are generally reported with decreased ambulance callouts.

\section{Discussion}

A temperature of mean $T 34^{\circ} \mathrm{C}$ would provide a suitable threshold to advise ambulance services of expected increase in service demand. Mean $T$ is measured using $24 \mathrm{hr}$ average temperature; this includes the effects of a hot day followed by a hot night, highlighting the effect of prolonged heat exposure on population health. When this threshold is exceeded, a 9\% increase in emergency callouts was observed; this would place a considerable burden on service provision. In Brisbane areas with more aged care facilities, higher urban density 

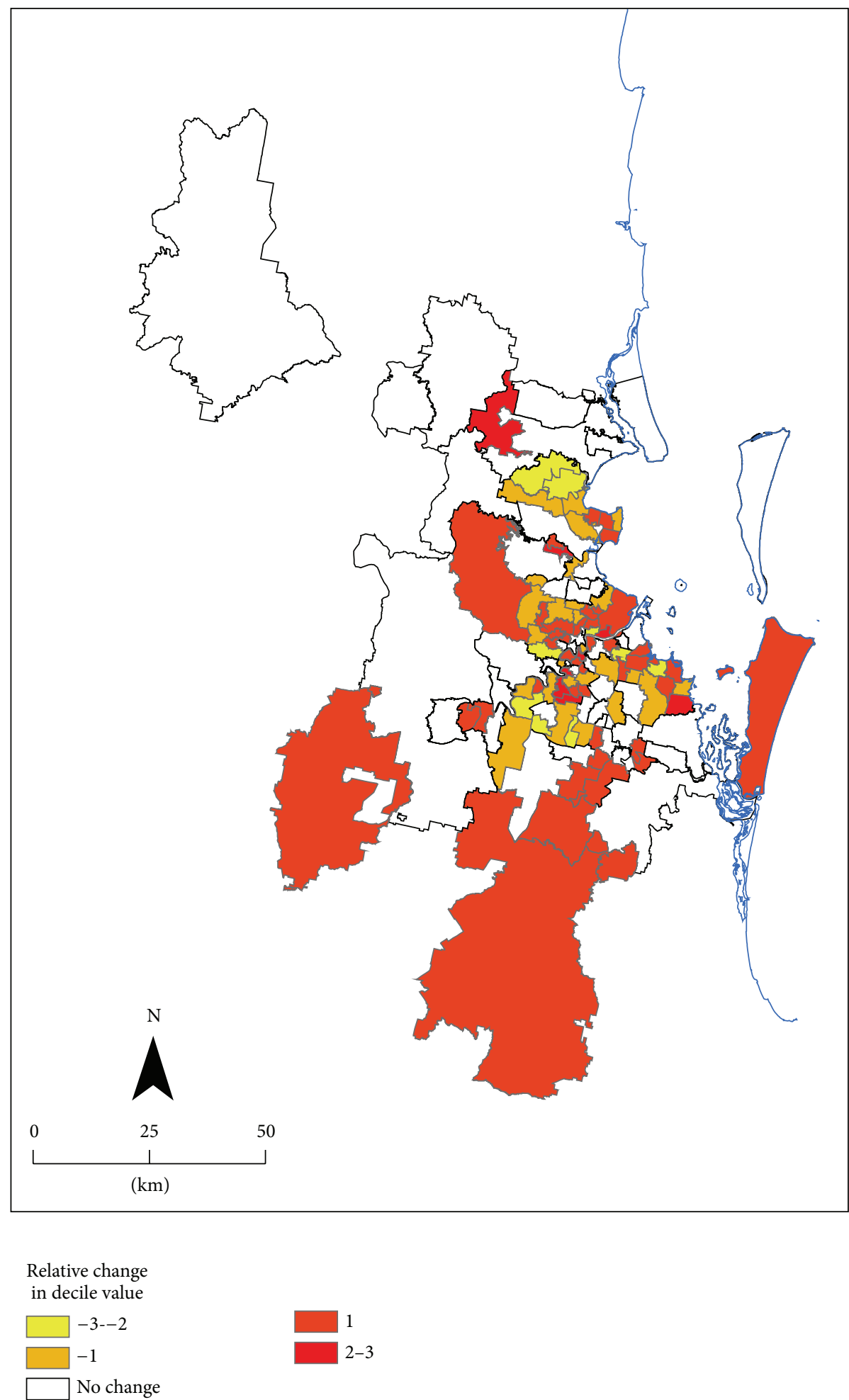

FIGURE 5: Relative change in decile value of ambulance callouts between baseline (summer nonhot days) and hot days in Brisbane (based on 1/7/2003-4/8/2011 data). Blank (white) POA indicates that there was no difference in ambulance callout decile value, whereas yellow and orange POA indicate a lower ambulance callout decile value on hot days as compared with summer nonhot days. Red indicates an increase in demand for ambulance services on hot days. 
and persons living alone (older people) presented the greatest risk during heatwaves. This provides information for policy development and infrastructure planning to make sure that adaptation can be enacted in the areas of greatest need.

The unstandardized coefficients from stepwise regression analysis in (2) indicated that areas with larger numbers of older people especially those living alone in higher density urban areas have a positive correlation with the adverse health outcomes on hot days. This result supports previous literature $[40,42,43,46,47]$ indicating that elderly people and people living in multiple dwellings and apartments can have a higher vulnerability level than others during hot days. A study of older people living in region that routinely experiences hot summers indicated that behavioural and technological adaptation at a personal level was an effective way of reducing heat exposure during extreme heat events [48].

In the Brisbane area higher vulnerability is noted in clusters along the coast and the inner western suburbs (see Figure 1). Similarly emergency callouts on hot days show higher demand in coastal areas and the inner west (see Figure 2). By contrast, areas to the east of Brisbane city, and towards the west, show a lower level of vulnerability (see Figure 1) but a higher demand for services on days exceeding the thresholds (see Figure 2). This may be heat exposure in either the workplace or recreational areas as opposed to areas where people live or an increased dependence on emergency services such as ambulances. The vulnerability variables are characteristics of where people live and are not necessarily related to occupation or recreation. Emergency managers and public health authorities need to be aware of these differences and focus on adaptation and mitigation plans to increase resilience in these areas. Such an uneven distribution of emergency service demand on hot days among POA in the city highlights the need to prioritise areas for emergency service provision.

In Figure 3 the areas to the north, the west of the city, and the southern urban fringe show a marked increase in population density and potentially an increase in UHI. The proportional change in older residents is greatest in the areas along the coast and eastern Brisbane (see Figure 4). All these areas currently show high levels of heat-related vulnerability and high numbers of ambulance calls on days exceeding the threshold. These areas should be targeted for heatwave planning and preventive care.

This study had some limitations; these include using satellite LST as a proxy for ambient air temperature. However satellite data does show areas where building mass retains heat and limits night-time cooling. Other factors affect heat exposure that could not be included in the index, such as solar radiation, humidity, air movement, and the ability to seek shelter. The index is based on variables linked to the environment where people live; future indices may be able to expand to include occupational risk and exposure in recreational places such as beaches and parks. Estimation of accessibility to emergency services only considers the transportation (by distance and time) between incident locations to the nearest emergency services. Factors that can also be used in vulnerability adaptation and resilience assessments such as emergency response time (duration between the time when patients contacted ES and service arrived on scene) were not available and thus not accounted for in this study.

\section{Conclusions}

The main aim of this study was to develop a holistic approach to understanding heat-related morbidity and provide information to aid public health authorities in planning emergency management preparedness and response strategies during heatwaves. Threshold temperatures at which ambulance callouts increased were identified and areas with excess callouts days exceeding the thresholds were mapped to demonstrate areas of increased heat-related service demand. When preparing heatwave adaptation plans, incorporating a measure of future estimated risk is important. This study used projected changes in population to estimate heatwave risks and produced maps showing the changes from baseline or current risk. Understanding risk is an important part of emergency service preparedness and planning. However, to date this has been limited to defining heatwave thresholds and documenting the health impacts. The mapping tool developed here provides a relevant measure of impact using readily available and reliable data sources that is transferable to all larger cities.

\section{Conflict of Interests}

The authors declare that there is no conflict of interests regarding the publication of this paper.

\section{References}

[1] J. Reeves, C. Foelz, P. Grace et al., Impacts and Adaptation Response of Infrastructure and Communities to Heatwaves: the Southern Australian Experience of 2009, Queensland University Technology and National Climate Change Adaptation Research Facility, Brisbane, Australia, 2010.

[2] H. Cleugh, M. Stafford Smith, M. Battaglia, and P. Graham, Eds., CSIRO. Climate Change: Science and Solutions for Australia, CSIRO Publishing, 2011, http://www.csiro.au/Outcomes/Climate/Climate-Change-Book.aspx.

[3] IPCC, "Managing the risks of extreme events and disasters to advance climate change adaptation," in A Special Report of Working Groups I and II of the Intergovernmental Panel on Climate Change, C. B. Field, V. Barros, T. F. Stocker et al., Eds., p. 582, Cambridge University Press, Cambridge, UK, 2012, http://ipcc-wg2.gov/SREX/images/uploads/SREX-All_FINAL .pdf.

[4] G. Brücker, "Vulnerable populations: lessons learnt from the summer 2003 heat waves in Europe," Euro Surveillance, vol. 10, no. 7-9, p. 147, 2005.

[5] J.-M. Robine, S. L. K. Cheung, S. Le Roy et al., "Death toll exceeded 70,000 in Europe during the summer of 2003," Comptes Rendus, vol. 331, no. 2, pp. 171-178, 2008.

[6] A. Fouillet, G. Rey, F. Laurent et al., "Excess mortality related to the August 2003 heat wave in France," International Archives of Occupational and Environmental Health, vol. 80, no. 1, pp. 16$24,2006$. 
[7] K. Katsouyanni, D. Trichopoulos, X. Zavitsanos, and G. Touloumi, "The 1987 Athens heatwave," The Lancet, vol. 2, no. 8610, p. $573,1988$.

[8] C. Rooney, A. J. McMichael, R. S. Kovats, and M. P. Coleman, "Excess mortality in England and Wales, and in Greater London, during the 1995 heatwave," Journal of Epidemiology and Community Health, vol. 52, no. 8, pp. 482-486, 1998.

[9] H. Johnson, R. S. Kovats, G. McGregor et al., "The impact of the 2003 heat wave on mortality and hospital admissions in England," Health Statistics Quarterly, no. 25, pp. 6-11, 2005.

[10] S. Whitman, G. Good, E. R. Donoghue, N. Benbow, W. Shou, and S. Mou, "Mortality in Chicago attributed to the July 1995 heat wave," The American Journal of Public Health, vol. 87, no. 9, pp. 1515-1518, 1997.

[11] P. J. Nogueira, J. M. Falcão, M. T. Contreiras, E. Paixão, J. Brandão, and I. Batista, "Mortality in Portugal associated with the heat wave of August 2003: early estimation of effect, using a rapid method," Euro Surveillance, vol. 10, no. 7, pp. 150-153, 2005.

[12] J. Garssen, C. Harmsen, and J. de Beer, "The effect of the summer 2003 heat wave on mortality in the Netherlands," Euro Surveillance, vol. 10, no. 7, pp. 165-168, 2005.

[13] F. Simón, G. Lopez-Abente, E. Ballester, and F. Martínez, "Mortality in Spain during the heat waves of summer 2003," Euro Surveillance, vol. 10, no. 7-9, pp. 156-161, 2005.

[14] S. Hoshiko, P. English, D. Smith, and R. Trent, "A simple method for estimating excess mortality due to heat waves, as applied to the 2006 California heat wave," International Journal of Public Health, vol. 55, no. 2, pp. 133-137, 2010.

[15] Agence France-Presse, "Moscow mortality soars amid heatwave," The Age. August 2010, http://news.theage.com.au/breaking-news-world/moscow-mortality-soars-amid-heatwave20100806-11li6.html.

[16] D. S. Battisti and R. L. Naylor, "Historical warnings of future food insecurity with unprecedented seasonal heat," Science, vol. 323, no. 5911, pp. 240-244, 2009.

[17] Y. Honda, M. Ono, A. Sasaki, and I. Uchiyama, "Shift of the short-term temperature mortality relationship by a climate factor-some evidence necessary to take account of in estimating the health effect of global warming," Journal of Risk Research, vol. 1, no. 3, pp. 209-220, 1998.

[18] W.-H. Pan, L.-A. Li, and M.-J. Tsai, “Temperature extremes and mortality from coronary heart disease and cerebral infarction in elderly Chinese," The Lancet, vol. 345, no. 8946, pp. 353-355, 1995.

[19] Y. Y. Yan, "The influence of weather on human mortality in Hong Kong," Social Science and Medicine, vol. 50, no. 3, pp. 419427, 2000.

[20] H. Kim, J.-S. Ha, and J. Park, "High temperature, heat index, and mortality in 6 major cities in South Korea," Archives of Environmental and Occupational Health, vol. 61, no. 6, pp. 265270, 2006.

[21] H.-D. Kan, J. Jia, and B.-H. Chen, "Temperature and daily mortality in Shanghai: a time-series study," Biomedical and Environmental Sciences, vol. 16, no. 2, pp. 133-139, 2003.

[22] R. Akhtar, "Climate change and health and heat wave mortality in India," Global Climate Research, vol. 11, no. 1, pp. 51-57, 2007.

[23] K. Burkart, M. H. Khan, A. Krämer, S. Breitner, A. Schneider, and W. R. Endlicher, "Seasonal variations of all-cause and causespecific mortality by age, gender, and socioeconomic condition in urban and rural areas of Bangladesh," International Journal for Equity in Health, vol. 10, article 32, 2011.
[24] L. Coates, Ed., Conference of Natural Disaster Reduction, Gold Coast, Australia, 1996.

[25] A. Hansen, P. Bi, M. Nitschke, D. Pisaniello, J. Newbury, and A. Kitson, "Perceptions of heat-susceptibility in older persons: Barriers to adaptation," International Journal of Environmental Research and Public Health, vol. 8, no. 12, pp. 4714-4728, 2011.

[26] Victorian Government Department of Human Services, 2009, http://www.health.vic.gov.au/chiefhealthofficer/publications/ heatwave.htm.

[27] Auditor General of Queensland, Queensland Audit Office, Report No. 2, 2004-2005: Audit of the Queensland Disaster Management System, 2004, http://www.ga.gov.au/image_cache/ GA4213.pdf.

[28] S. Tong, C. Ren, and N. Becker, "Excess deaths during the 2004 heatwave in Brisbane, Australia," International Journal of Biometeorology, vol. 54, no. 4, pp. 393-400, 2010.

[29] W. Yu, W. Hu, K. Mengersen et al., "Time course of temperature effects on cardiovascular mortality in Brisbane, Australia," Heart, vol. 97, no. 13, pp. 1089-1093, 2011.

[30] Y. Guo, A. G. Barnett, X. Pan, W. Yu, and S. Tong, “The impact of temperature on mortality in Tianjin, china: a case-crossover design with a distributed lag nonlinear model," Environmental Health Perspectives, vol. 119, no. 12, pp. 1719-1725, 2011.

[31] C. Huang, A. G. Barnett, X. Wang, and S. Tong, "The impact of temperature on years of life lost in Brisbane, Australia," Nature Climate Change, vol. 2, no. 4, pp. 265-270, 2012.

[32] L. V. Alexander and J. M. Arblaster, "Assessing trends in observed and modelled climate extremes over Australia in relation to future projections," International Journal of Climatology, vol. 29, no. 3, pp. 417-435, 2009.

[33] A. Auliciems and L. Di Bartolo, "Domestic Violence in a subtropical environment: police calls and weather in Brisbane," International Journal of Biometeorology, vol. 39, pp. 34-39, 1995.

[34] A. Auliciems and J. L. Skinner, "Cardiovascular deaths and temperature in subtropical Brisbane," International Journal of Biometeorology, vol. 33, no. 4, pp. 215-221, 1989.

[35] X. Y. Wang, A. G. Barnett, W. Yu et al., "The impact of heatwaves on mortality and emergency hospital admissions from non-external causes in Brisbane, Australia," Occupational and Environmental Medicine, vol. 69, no. 3, pp. 163-169, 2012.

[36] M. S. O’Neill, A. Zanobetti, and J. Schwartz, "Modifiers of the temperature and mortality association in seven US cities," American Journal of Epidemiology, vol. 157, no. 12, pp. 1074-1082, 2003.

[37] M. Loughnan, N. Nicholls, and N. Tapper, "Mortality-temperature thresholds for ten major population centres in rural Victoria, Australia," Health and Place, vol. 16, no. 6, pp. 12871290, 2010.

[38] N. Nicholls, C. Skinner, M. Loughnan, and N. Tapper, "A simple heat alert system for Melbourne, Australia," International Journal of Biometeorology, vol. 52, no. 5, pp. 375-384, 2008.

[39] SPSS, Version 19 Statistical Package for Social Science, SPSS, Chicago, Ill, USA, 2011.

[40] S. L. Cutter, B. J. Boruff, and W. L. Shirley, "Social vulnerability to environmental hazards," Social Science Quarterly, vol. 84, no. 2, pp. 242-261, 2003.

[41] R. Few, "Health and climatic hazards: framing social research on vulnerability, response and adaptation," Global Environmental Change, vol. 17, no. 2, pp. 281-295, 2007. 
[42] D. P. Johnson, A. Stanforth, V. Lulla, and G. Luber, "Developing an applied extreme heat vulnerability index utilizing socioeconomic and environmental data," Applied Geography, vol. 35, no. 1, pp. 23-31, 2012.

[43] M. Stafoggia, F. Forastiere, D. Agostini et al., "Vulnerability to heat-related mortality: a multicity, population-based, casecrossover analysis," Epidemiology, vol. 17, no. 3, pp. 315-323, 2006.

[44] C. E. Reid, M. S. O’Neill, C. J. Gronlund et al., "Mapping community determinants of heat vulnerability," Environmental Health Perspectives, vol. 117, no. 11, pp. 1730-1736, 2009.

[45] Queensland Government, "Projected population (medium series) by statistical local area and five-year age group and sex," Queensland, 30 June, 2006 to 2031, 2012, http://www.oesr .qld.gov.au/subjects/demography/population-projections/tables/proj-pop-medium-series-sla-age-sex-qld/index.php.

[46] S. Vandentorren, P. Bretin, A. Zeghnoun et al., "August 2003 heat wave in France: risk factors for death of elderly people living at home," European Journal of Public Health, vol. 16, no. 6, pp. 583-591, 2006.

[47] S. Vandentorren, F. Suzan, S. Medina et al., "Mortality in 13 French cities during the August 2003 heat wave," American Journal of Public Health, vol. 94, no. 9, pp. 1518-1520, 2004.

[48] M. Loughnan, M. Carroll, and N. J. Tapper, "Learning from our Elders: Pilot study findings on responding to heat," Australiasian Journal on Ageing, vol. 23, no. 1, 2013.

[49] The ABS BCP for Brisbane, http://www.censusdata.abs.gov .au/ABSNavigation/prenav/ViewData?\&action=404\&documentproductno $=305 \&$ documenttype $=$ Details $\&$ tabname $=$ Details $\&$ areacode $=305 \&$ issue $=2006 \&$ producttype $=$ Community $\% 20$ Profiles\&\&producttype $=$ Community $\% 20$ Profiles\&javascript=true\& textversion=false\&navmapdisplayed=true\&breadcrumb=PLD\& \&collection=Census\&period $=2006 \&$ producttype $=$ Community\%20Profiles\&\#Basic.

[50] SEIFA, http://www.abs.gov.au/websitedbs/censushome.nsf/home/ seifapast?opendocument\&navpos=260.

[51] M. Zdeb, Driving Distances and Times Using SAS and Google Maps, 2010, http://support.sas.com/resources/papers/proceedings10/050-2010.pdf. 


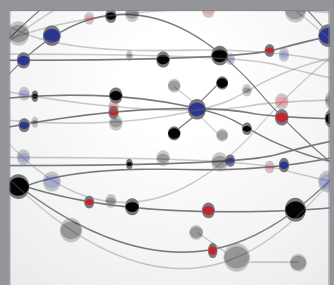

The Scientific World Journal
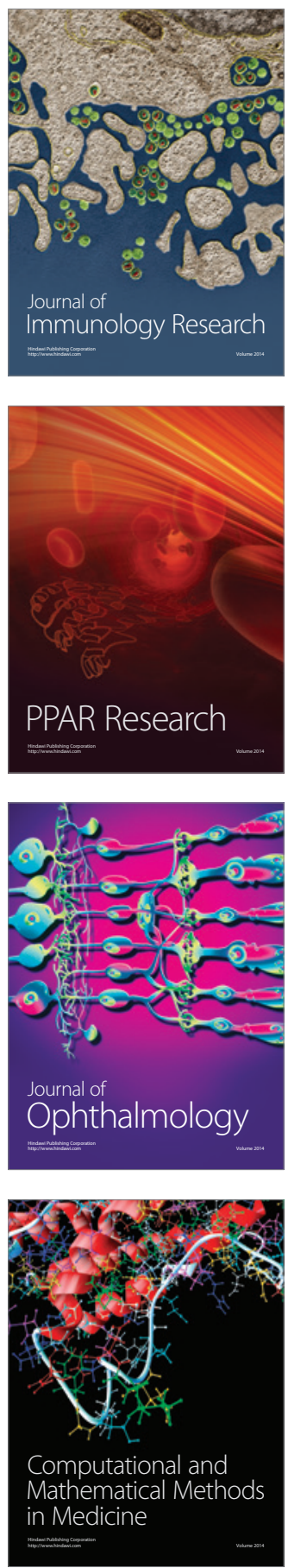

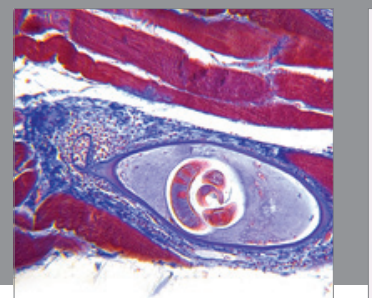

Gastroenterology

Research and Practice
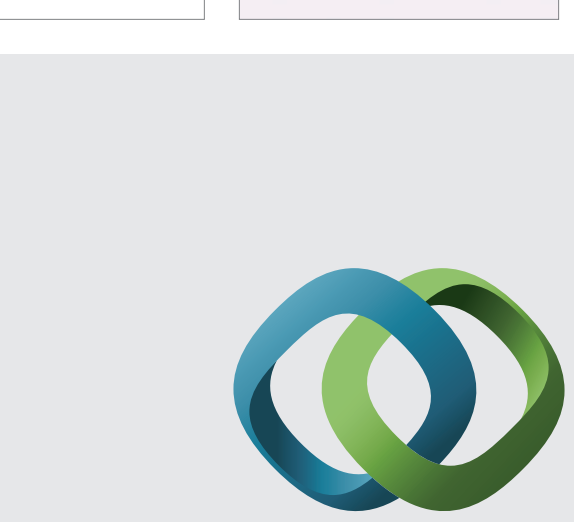

\section{Hindawi}

Submit your manuscripts at

http://www.hindawi.com
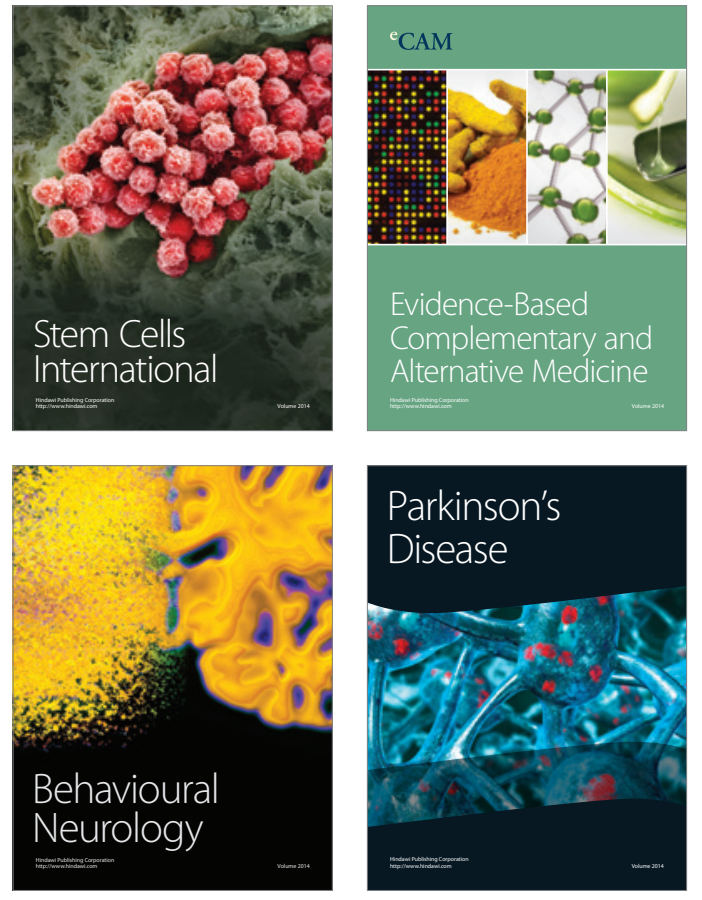
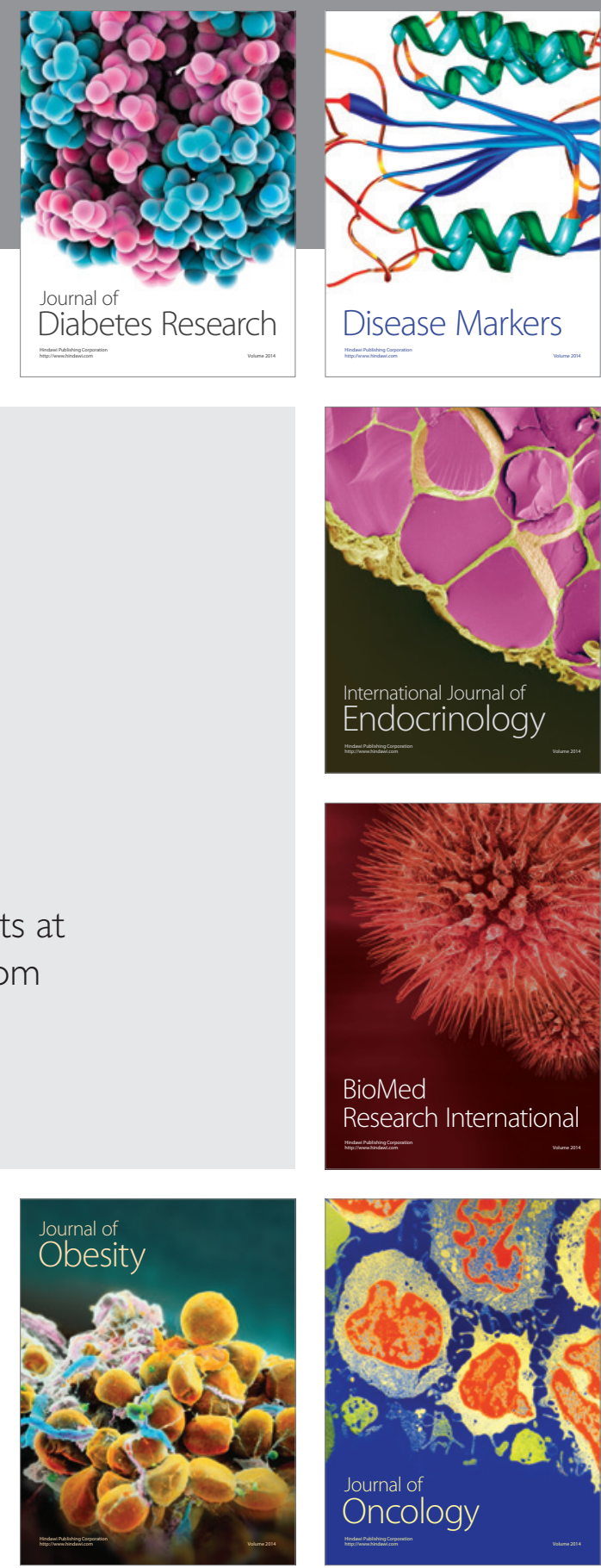

Disease Markers
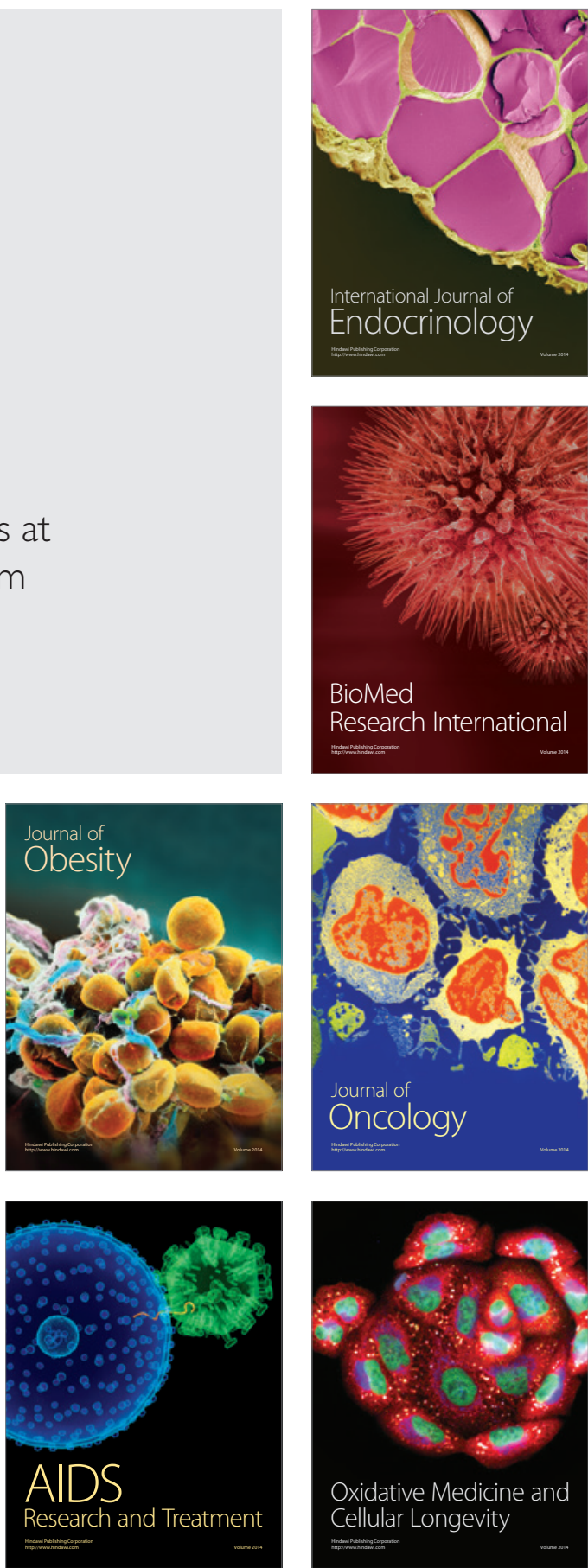